\title{
RENAL RICKETS FOLLOWING ACQUIRED NEPHRITIS
}

BY

\author{
V. H. ELLIS, F.R.C.S., \\ Orthopædic Surgeon, St. Mary's Hospital, London.
}

In the previous number of the 'Archives of Disease in Childhood,' E. A. Cockayne and F. P. Lee Lander', under the title of ' rickets following an attack of acute nephritis,' recorded a case in which the bony changes of renal rickets had supervened in a previously healthy child who had contracted a severe nephritis. In their comments they remarked on the fact that medical literature contained hardly any reference to this type of case.

Their communication has prompted me to report the following two cases which appear to be of the same type as their own.

\section{Case reports.}

Case 1.-William H., aged 17 years. In July, 1922, he was admitted to a fever hospital with acute nephritis. There was a history of a scarlatiniform rash a short time previously. While in hospital his albuminuria diminished considerably but had not completely disappeared at the time of his discharge.

His mother states that up to the time of this illness he was quite normal, but that since then his growth has been much retarded.

He was first diagnosed as a case of renal rickets in 1928, and in the following year his blood urea measured $140 \mathrm{mgrm}$. per cent. At the present time, aged 17 years, he has the stature and appearance of a boy of 9 or 10 years. He is in fair health, but he has severe genu valgum. He shows typical radiological evidence of renal rickets.

Case 2.-Olive P., aged 14 years. In 1925 at the age of 7 years she had scarlet fever and nephritis. Since that time, according to her mother, she has been very backward. In July, 1931, her blood urea was 115 mgrm. per cent.; blood calcium 7 mgrm., and blood phosphate 6 mgrm. In April, 1932, she was admitted to hospital with a history of 1 year's increasing genu valgum. The $\mathrm{X}$-ray appearances were typical of renal rickets.

\section{Discussion.}

Renal rickets is usually described as a disease associated with congenital changes in the kidneys. Most commonly the kidneys have the appearance of chronic interstitial nephritis (Ashcroft ${ }^{2}$ ), although Brockman ${ }^{3}$ has met an instance with typical deformities associated with congenital cystic kidneys.

As regards the possible development of renal rickets as a sequel to an acquired acute nephritis it must necessarily be a matter of great difficulty to prove in any individual case that the kidneys were healthy until the onset of the acquired disease. Although deformities and stunted growth may not be noticed until after the acute attack this is not necessarily sufficient 
proof. It may be, that the acute nephritis has occurred in kidneys already diseased and so unmasked or hastened the onset of the symptoms of renal rickets. It is not so uncommon for cases of renal rickets to give a history of acute nephritis, and the difficulty of assessing accurately the value of the clinical history is enhanced by the fact that cases of renal rickets do not find their way to the orthopædic surgeon much before the age of ten years.

In the case reported by Cockayne and Lander there is one point which strongly supports their contention that there was no congenital disease of the kidneys: namely, that the symptoms in the chronic stages of the acquired nephritis were of the hydræmic type. Their long observation of the case and the conditions found post mortem also support their view. Barber $^{4}$ describes an interesting case (No. 7 in his series). The child had a history of diabetes insipidus at the age of three years, but although the urine was examined many times, no albuminuria was ever found. After an attack of scarlet fever the child developed deformities and albuminuria. It does not seem possible to exclude the presence of renal disease in early life on this history.

Many orthopædic surgeons would readily allow that renal rickets may follow acquired nephritis or even chronic pyelo-nephritis; but owing presumably to the difficulty in the production of satisfactory proofs, there is little reference to such cases in the literature.

\section{REFERENCES.}

1. Cockayne, E. A., \& Lander, F. P. L., Arch. Dis. Childh., Lond., 1932, VII, 321.

2. Ashcroft, G. V., J. Bone \& Joint Surg., Boston, 1926, VIII, 279.

3. Brockman, E. P., Brit. J. Surg., Bristol, 1927, XIV, 634.

4. Barber, H., Quart. J. Med., Oxford, 1921, XIV, 205. 